\title{
Neuregulin 1 enhances cell adhesion molecule L1 like expression levels and promotes malignancy in human glioma
}

\author{
WEN-WEN LIN ${ }^{1 *}$, GUAN-YONG OU ${ }^{1 *}$, JIA-ZHE LIN $^{2 *}$, SAN-JUN YI ${ }^{1}$, \\ WEI-CHENG YAO ${ }^{3}$, HONG-CHAO PAN ${ }^{1}$ and WEI-JIANG ZHAO ${ }^{1,4}$ \\ ${ }^{1}$ Center for Neuroscience, Shantou University Medical College; ${ }^{2}$ Neurosurgical Department, \\ The First Affiliated Hospital of Shantou University Medical College, Shantou, Guangdong 515041; \\ ${ }^{3}$ Medical Research Center, Sun Yat-Sen Memorial Hospital, Sun Yat-Sen University, Guangzhou, Guangdong 510120; \\ ${ }^{4}$ Cell Biology Department, Wuxi School of Medicine, Jiangnan University, Wuxi, Jiangsu 214122, P.R. China
}

Received September 7, 2019; Accepted February 28, 2020

DOI: $10.3892 / \mathrm{ol} .2020 .11548$

\begin{abstract}
Neural cell adhesion molecular L1-like protein (CHL1) is a member of the cell adhesion molecule L1 family and serves an important role in the development and progression of tumors. The cytokine neuregulin 1 (NRG1) has been indicated in the tumorigenesis and promotion of metastasis through the modulation of L1. However, the roles of NRG1 in regulating CHL1 in glioma have not been elucidated. The present study investigated the protein expression levels and roles of CHL1 and the possible correlation between NRG1 and CHL1 protein expression levels in human gliomas, both in vivo and in vitro. Using immunohistochemistry coupled with a human glioma tissue microarray, it was demonstrated that the percentage of CHL1-positive areas was the highest in grade II glioma tissues. Using immunofluorescence staining, a positive correlation was identified between the expression levels of CHL1 and proliferating cell nuclear antigen. In addition, CHL1 downregulation also resulted in increased senescence of U-87 MG human glioblastoma cells. In vitro, administration of NRG1 $\alpha$ induced a significant increase in CHL1 protein expression levels in human glioma SHG-44 and U251 cells and in human glioblastoma U-87 MG cells, whereas NRG1 $\beta$ failed to increase CHL1 expression levels in U251 cells. These findings were further confirmed by the downregulation of NRG1 expression levels using small interfering RNA treatment, which resulted in the reduction of CHL1 protein expression levels in U-87 MG cells. These data indicate that NRG1 can regulate $\mathrm{CHL} 1$ protein expression levels in gliomas, that it is
\end{abstract}

Correspondence to: Professor Wei-Jiang Zhao, Cell Biology Department, Wuxi School of Medicine, Jiangnan University, 1800 Lihu Dadao Road, Wuxi, Jiangsu 214122, P.R. China

E-mail: weijiangzhao@jiangnan.edu.cn

*Contributed equally

Key words: glioma, glioblastoma, neuregulin 1, cell adhesion molecule L1 like, glioma cell line, tissue array correlated with malignancy, and that NRG1 may contribute to malignancy by upregulating CHL1 protein expression levels in glioma/glioblastoma cells.

\section{Introduction}

Malignant gliomas account for $\sim 70 \%$ of human primary malignant brain tumors annually in the United States and can lead to a median survival of only 12-15 months, even with optimal treatment such as strategies to increase the radiation dose and novel chemotherapeutic agents (1). Gliomas are histologically heterogeneous and invasive tumors, which are derived from abnormal proliferative glial cells and gliomas are characterized by the sequential accumulation of genetic aberrations such as Olig2 and the deregulation of the growth-factor signaling pathway (2). Treatment options at diagnosis often consist of a combination of surgery, radiotherapy and chemotherapy (3). However, the benefit of surgical resection in prolonging overall survival rate remains limited due to the infiltrative nature of glioma, which usually leads to recurrence (1). Despite the application of standard treatment, including radio-chemotherapy with the alkylating agent temozolomide (4), the median survival time is $<2$ years due to treatment resistance $(5,6)$, and little progress has been made in the field of glioma treatment (7). With invasion and metastasis being the most devastating difficulties in the clinical management of glioma, understanding the underlying pathogenic mechanisms of gliomas is important, including an understanding of the cytokines potentially involved in the development and progression of gliomas.

The regulatory effects of cytokines on tumors have been intensively investigated (8-10). Neuregulins (NRGs) are cytokines associated with a variety of different malignant tumors, which function as signaling molecules that mediate cellular interactions. For example, NRG1 was found increase the risk of bladder cancer development (11), uveal melanoma (12) and node-negative invasive breast cancer (13). NRG1, as an epidermal growth factor (EGF)-like family member, is one of the most active malignant tumor-related cytokines, with $\geq 6$ identified isoforms resulting from alternative splicing of the NRG1 gene, including Type I to III NRG1 $\alpha$ and NRG1 $\beta$ (14). 
After binding to the receptor tyrosine-protein kinase erbB-2 (also called NEU), NRG1 initiates intracellular responses, including proliferation stimulation and inhibition, apoptosis, migration, differentiation and adhesion (13). Ritch et al (15) demonstrated that glioma cell survival is enhanced via either an autocrine or a paracrine NRG1/ErbB receptor signaling pathway.

Cell adhesion molecule L1 like(CHL1) encodes a single-pass transmembrane cell adhesion molecule (CAM) that is capable of both homophilic and heterophilic interactions (16). CHL1 is a member of the neural CAM L1 family (16), which comprises 4 structurally related transmembrane proteins in vertebrates: L1, CHL1, neuronal cell adhesion molecule (NrCAM) and neurofascin (17). Similar to L1, CHL1 is also involved in cell adhesion, axon guidance and synaptic plasticity (18). Accumulating evidence has also indicated that CHL1 serves a significant role in tumor metastasis and progression $(19,20)$.

Our previous research indicated that NRG1 promotes glioma cell migration by enhancing the protein expression levels of L1 $(21,22)$. In the present study, the correlation between CHL1 and glioma grade and the role of NRG1 in modulating L1 was investigated. The results demonstrated that both NRG1 $\alpha$ and NRG1 $\beta$ promote glioma cell migration by enhancing CHL1 expression levels, possibly by controlling the ERK pathway. This may provide insight into the development of inhibitors to antagonize NRG1-induced CHL1 expression in the treatment of glioma.

\section{Materials and methods}

Reagents and microarray. A total of 2 recombinant $E$. coli-derived NRG1 1 (rNRG1 $\alpha$, RP-317-P0A; Thermo Fisher Scientific, Inc.) and NRG1 $\beta 1$ (rNRG1 $\beta$, RP-318-P0A; Thermo Fisher Scientific, Inc.) isoforms, corresponding to the extracellular domains of the 2 molecules were used. A rat anti-human CHL1 antibody specifically targeting the extracellular domain of CHL1 was purchased from R\&D Systems, Inc. (1:200 for both immunohistochemistry and immunuofluorescence, and 1:500 for western blot analysis; cat. no. MAB2126) and an anti-rabbit phosphorylated(p)-Neu antibody (1:200; cat. no. sc-101695) was purchased from Santa Cruz Biotechnology, Inc. A donkey anti-rat secondary antibody conjugated to Alexa Fluor 488 (1:500; cat. no. 712-545-153), a donkey anti-rat secondary antibody conjugated to Dylight ${ }^{\mathrm{TM}} 594$ (1:1,000; cat. no. 712-515-150), a donkey anti-mouse secondary antibody conjugated to Dylight $^{\mathrm{TM}} 488$ (1:500; cat. no. 715-485-150) and a donkey anti-rabbit secondary antibody conjugated to Dylight ${ }^{\mathrm{TM}} 594$ (1:1,000; cat. no. 711-515-152) were all purchased from Jackson ImmunoResearch Laboratories, Inc. A mouse monoclonal anti-NRG1 antibody (1:500; cat. no. MA5-12896; Thermo Fisher Scientific, Inc.), a mouse monoclonal anti-PCNA antibody (1:200; cat. no. sc-25280; Santa Cruz Biotechnology, Inc.), a mouse monoclonal anti-ERK1/2 antibody $(1: 1,000$; cat. no. sc-135900; Santa Cruz Biotechnology, Inc.), a mouse monoclonal anti-p-ERK1/2 antibody (1:1,000; cat. no. sc-7383; Santa Cruz Biotechnology, Inc.), a mouse monoclonal anti-GAPDH antibody (1:1,000; cat. no. sc-3650620; Santa Cruz Biotechnology, Inc.) and horseradish peroxidase-conjugated goat anti-mouse $(1: 1,000$; cat. no. BA1050; Wuhan
Boster Biological Technology, Ltd.) and rabbit anti-rat secondary antibodies (1:1,000; cat. no. BA1058; Wuhan Boster Biological Technology, Ltd.) were used. Dulbecco's modified Eagle's medium (HyClone; Thermo Fisher Scientific, Inc.), penicillin/streptomycin mixture (Beijing Solarbio Science and Technology Co., Ltd.), 10\% FBS (Hangzhou Sijiqing Biological Engineering Materials Co., Ltd.), 10\% normal goat serum and $10 \%$ normal donkey serum (Beijing Solarbio Science and Technology Co., Ltd.) were used. A human glioma microarray, containing 184 glioma tissues, which can be graded from I to IV and 18 cancer adjacent normal (CAN) tissues, was purchased from US Biomax, Inc. (cat. no. GL 2083). The tumors were graded by a licensed pathologist on a scale of I to IV according to their degree of malignancy as defined by the World Health Organization classification of tumors of the central nervous system (23): I, Pilocytic astrocytoma; II, fairly differentiated astrocytoma; III, anaplastic astrocytoma; and IV, glioblastoma.

Hematoxylin and eosin $(H \& E)$ and immunohistochemical staining. Immunohistochemical staining of paraffinized sections was performed as previously described (22). Human glioma tissue microarray sections $(4-\mu \mathrm{m}$ thick and deparaffinized) were rehydrated using a graded ethanol series (from $100,90,80,70,60$ to $50 \%$ ) that culminated with PBS. Antigen retrieval was performed using $10 \mathrm{mM}$ citrate buffer ( $\mathrm{pH}$ 6.0) at $99^{\circ} \mathrm{C}$ for $1 \mathrm{~h}$ and endogenous peroxidase was cleared by incubation in $3 \% \mathrm{H}_{2} \mathrm{O}_{2}$ at room temperature for $20 \mathrm{~min}$. The sections were then blocked with $10 \%$ normal goat serum in PBS at room temperature for $30 \mathrm{~min}$, and the samples were incubated at $4^{\circ} \mathrm{C}$ overnight with a rat-anti-human primary antibody targeting human CHL1 (1:100). The antigen-antibody complexes were visualized using the avidin-biotin-peroxidase complex method using an AEC kit (cat. no. ZLI-9036, Beijing Zhongshan Jinqiao Biotechnology Co., Ltd.). For H\&E staining, tissues were stained with eosin solution (cat. no. BSBA-4022, Beijing Zhongshan Jinqiao Biotechnology Co., Ltd.) for $5 \mathrm{~min}$ at room temperature. Counterstaining was performed with Mayer's hematoxylin (cat. no. BSBA-4021A, Beijing Zhongshan Jinqiao Biotechnology Co., Ltd.) for $1 \mathrm{~min}$ at room temperature. Images of the $\mathrm{H} \& \mathrm{E}$ and immunohistochemical staining results were captured using a light microscope (magnification, $\mathrm{x} 200$; http://www.jnoec.com). The percentage of the area that was positive for CHL1 staining on each whole tissue point was evaluated using ImageTool (IT) software [version 3.0; Department of Dental Diagnostic Science at the University of Texas Health Science Center (UTHSCSA); magnification, $\mathrm{x} 200$ ], which indicated the expression levels of CHL1 in the CAN tissue and glioma tissues graded from I to IV.

Cell culture. The human glioblastoma U-87 MG cell line (cat. no. CL-0238; unknown origin) and the human glioma U251 cell line (cat. no. CL-0237) were purchased from Procell Life Science and Technology Co., Ltd. The human glioma cell line SHG-44 (cat. no. SHG44) was purchased from Guangzhou Jennio Bioech Co., Ltd; http://www.jennio-bio.com.). All cell lines were authenticated using short tandem repeat analysis and tested for mycoplasma contamination. Cell lines were maintained in Dulbecco's modified Eagle's medium (HyClone; Thermo Fisher Scientific, Inc.) supplemented with $50 \mathrm{U} / \mathrm{ml}$ 
penicillin/streptomycin mixture (Beijing Solarbio Science and Technology Co., Ltd.) and 10\% fetal bovine serum (Hangzhou Sijiqing Biological Engineering Materials Co., Ltd.). The cells were routinely cultured in $75 \mathrm{~cm}^{2}$ cell culture plates (Corning Inc.) at $37^{\circ} \mathrm{C}$ in a humidified incubator with $5 \% \mathrm{CO}_{2}$.

Small interferring (si)RNA treatment. One control siRNA and siRNA against CHL1 (Table I), and one control siRNA and three different siRNAs against NRG1 (Table II), as well as the transfection reagent siRNA-Mate were purchased from Shanghai GenePharma Co., Ltd.. To test the effect of NRG1 on CHL1 expression, cells $\left(5 \times 10^{4}\right.$ cells/well) in normal culture medium were allowed to adhere overnight in 48 -well plates. When $80 \%$ confluence was achieved, the media were aspirated and replaced with fresh medium containing RNA/siRNA-Mate complexes $(10 \mathrm{nM}$ of either the random control siRNA or the targeting siRNAs/well) and the cells were further cultured at $37^{\circ} \mathrm{C}$ in a humidified incubator with $5 \% \mathrm{CO}_{2}$ for $48 \mathrm{~h}$ before western blot analysis.

To determine the effects of CHL1 on the level of proliferation cell nuclear antigen (PCNA), cells $\left(2 \times 10^{4} /\right.$ well $)$ in normal culture medium were allowed to adhere overnight in an 8-well Lab-Tek Chamber Slide ${ }^{\mathrm{TM}}$ (cat. no. 154941PK; Nalge Nunc International). The media were then aspirated and replaced with fresh medium containing RNA/siRNA-Mate complexes (10 $\mathrm{nM}$ of either the random control siRNA or the siRNA against CHL1/well) and the cells were further cultured for $48 \mathrm{~h}$. Cells were fixed with $4 \%$ paraformaldehyde in PBS $(\mathrm{pH} 7.3)$ at $4^{\circ} \mathrm{C}$ for $15 \mathrm{~min}$, and were then subjected to double immunofluorescence staining of both CHL1 and PCNA.

Cell senescence assay. The effects of CHL1 on cell senescence was assessed with the application of CHL1 siRNA in human glioblastoma U-87 MG cells. Cells ( $1 \times 10^{5}$ cells/well) in culture medium were allowed to adhere to 24-well plates overnight. When $80 \%$ confluence was achieved, the medium was aspirated and replaced with fresh medium containing RNA-siRNA-Mate complexes (10 nM of either the control or the CHL1 siRNA/well). The cells were further cultured at $37^{\circ} \mathrm{C}$ in a humidified incubator with $5 \% \mathrm{CO}_{2}$ for $48 \mathrm{~h}$. After $48 \mathrm{~h}$ of treatment, the cells were fixed for $20 \mathrm{~min}$ at $4^{\circ} \mathrm{C}$ with $4 \%$ paraformaldehyde in PBS. A $\beta$-galactosidase/X-Gal complex was added to each well and incubated overnight at $37^{\circ} \mathrm{C}$ according to the manufacturer's protocol (Beyotime Institute of Biotechnology). Cell senescence was determined by the development of a deep blue color in the cytoplasm, which reflected the activation of $\beta$-galactosidase.

Treatment with NRG1s. To investigate the effects of NRG1 $\alpha$ and $\beta$ on CHL1 expression levels and NRG1-induced activation of ERK1/2 in vitro, U-87 MG, U251 and SHG-44 cells $\left(1 \times 10^{5}\right.$ cells/well) were allowed to adhere to 24 -well plates (Costar; Corning Inc.). After an overnight incubation, the medium was aspirated and replaced with serum-free culture medium containing NRG1 $\alpha$ or NRG1 $\beta$ at concentrations of $0,0.5,1.0,1.5,2.5$ and $5.0 \mathrm{nM}$ for $48 \mathrm{~h}$. Cells were lysed using RIPA lysisbuffer mixture supplemented with PMSF (1:200; both Beijing Solarbio Science and Technology Co., Ltd.). The cell lysates were centrifuged at $14,000 \mathrm{xg}$ for $15 \mathrm{~min}$ at $4^{\circ} \mathrm{C}$, and the supernatants were collected for western blot analysis.
Table I. Sequences of control siRNA and siRNA targeting CHL1.

\begin{tabular}{lc}
\hline siRNA & \multicolumn{1}{c}{ Sequence, 5'-3' } \\
\hline $\begin{array}{l}\text { Random control } \\
\text { Sense }\end{array}$ & \\
Antisense & UUCUCCGAACGUGUCACGUTT \\
CHL1 & ACGUGACACGUUCGGAGAATT \\
Sense & \\
Antisense & GGAGCUAAUUUGACCAUAUTT \\
\hline
\end{tabular}

si, small interfering; CHL1, close homologue of L1.

Table II. Sequences of control siRNA and siRNA targeting NRG1.

siRNA Sequence, 5'-3'

Random control

Sense

Antisense

UUCUCCGAACGUGUCACGUTT

No. 1 (NRG1)

Sense

Antisense

ACGUGACACGUUCGGAGAATT

No. 2 (NRG1)

Sense

Antisense

GGCUGAUUCUGGAGAGUAUTT

AUACUCUCCAGAAUCAGCCTT

No. 3 (NRG1)

Sense

Antisense

GAGUCUCCCAUUAGAAUAUTT

AUAUUCUAAUGGGAGACUCTT

GCCACUCUGUAAUCGUGAUTT

AUCACGAUUACAGAGUGGCTT

si, small interfering; NRG1, neuregulin 1 .

For immunofluorescence staining, $2 \times 10^{4}$ cells/well were seeded overnight on an 8-well Lab-Tek Chamber Slide ${ }^{\mathrm{TM}}$ (Nunc). After the overnight incubation, the medium was aspirated and replaced with serum-free culture medium containing NRG1 $\alpha$ or NRG1 $\beta$ at concentrations of $2.5 \mathrm{nM}$ for $48 \mathrm{~h}$. The cells were then subjected to fixation with $4 \%$ paraformaldehyde in PBS (pH 7.3) at $4^{\circ} \mathrm{C}$ for $15 \mathrm{~min}$, which was followed by immunofluorescence staining for both CHL1 and p-Neu, as aforementioned.

Western blotting. Cells were then lysed with RIPA buffer (Solarbio Life Sciences). The cell lysate was then subjected to concentration determination with a BCA kit (Solarbio Life Sciences). A total of $20 \mu \mathrm{g}$ of protein from each cell lysate were heated at $95^{\circ} \mathrm{C}$ in $20 \%$ sample loading buffer $(0.125 \mathrm{M}$ Tris-HCl, pH 6.8, $20 \%$ glycerol, $10 \%$ SDS, $0.1 \%$ bromophenol blue and 5\% $\beta$-mercaptoethanol), then resolved using SDS-PAGE (with an $8 \%$ gel) and transferred onto polyvinylidene difluoride membranes (EMD Millipore). Non-specific protein binding sites were blocked with 5\% skimmed milk diluted in Tris-buffered saline ( $\mathrm{pH}$ 7.4) buffer containing $0.05 \%$ Tween-20 (TBST). The membranes were incubated overnight at $4{ }^{\circ} \mathrm{C}$ with a mouse monoclonal anti-NRG1 antibody, a rat 
anti-human CHL1 antibody, a mouse monoclonal anti-ERK1/2 antibody and a mouse monoclonal anti-p-ERK1/2 antibody. To control protein loading, a mouse monoclonal anti-GAPDH antibody was used to blot the membrane overnight at $4{ }^{\circ} \mathrm{C}$. After 3 washes of $5 \mathrm{~min}$ each with TBST at room temperature, horseradish peroxidase-conjugated goat anti-mouse and rabbit anti-rat secondary antibodies diluted in TBST were incubated with the membranes for $1 \mathrm{~h}$ at room temperature, which was followed by 3 washes with TBST for $5 \mathrm{~min}$ each at room temperature. The antigens were visualized using enhanced chemiluminescence (Beyotime Institute of Biotechnology). The signal intensity was quantified using IT software as the average densitometry multiplied by the area (measured as the number of pixels) (22).

Immunofluorescence analysis. Deparaffinized human glioma tissue microarray sections (4- $\mu \mathrm{m}$ thick and deparaffinized) were rehydrated through incubation with a graded ethanol series (from 100, 90, 80, 70, 60 to $50 \%$ ) that culminated with PBS. Antigen retrieval was performed using $10 \mathrm{mM}$ citrate buffer $(\mathrm{pH} 6.0)$ at $100^{\circ} \mathrm{C}$ for $1 \mathrm{~h}$. The samples were blocked with $10 \%$ normal donkey serum (Beijing Solarbio Science and Technology Co., Ltd.) in PBS at room temperature for $60 \mathrm{~min}$. The sections were incubated with the following primary antibodies: Rat anti-human CHL1 (1:200) and rabbit anti-PCNA antibodies (1:200). The cultured cells were incubated with rat anti-human CHL1 (1:200) antibody together with either mouse anti-PCNA antibody (1:200) or rabbit anti-p-Neu antibody (1:100). After being washed in PBS 3 times for $5 \mathrm{~min}$, the cells were incubated at room temperature for $90 \mathrm{~min}$ with a donkey anti-rat secondary antibody conjugated to Dylight ${ }^{\mathrm{TM}} 488$ (1:500) and a donkey anti-rabbit secondary antibody conjugated to Dylight ${ }^{\mathrm{TM}} 594$ (1:1,000). After being washed in PBS 3 times for $5 \mathrm{~min}$, the tissue samples were incubated at room temperature for 90 min with a donkey anti-mouse secondary antibody conjugated to Dylight ${ }^{\mathrm{TM}} 488$ (1:500) and a donkey anti-rat secondary antibody conjugated to Dylight ${ }^{\mathrm{TM}} 594(1: 1,000)$. The tissues and cells were co-stained with DAPI at room temperature for $20 \mathrm{~min}$ and mounted using an anti-fade mounting solution (Beyotime Institute of Biotechnology). Confocal images were captured using an Olympus confocal system (FV-1000; Olympus Corporation). DAPI, Dylight $^{\mathrm{TM}} 488$ and Dylight ${ }^{\mathrm{TM}} 594$ were excited at 405, 488 and $594 \mathrm{~nm}$, respectively.

Correlation analysis between CHL1 and PCNA. CHL1 and PCNA immunofluorescence images for each sample were rearranged onto one panel based on the tumor grade. The protein level (measured as the integrated immunofluorescence intensity) was evaluated on the basis of gray scale ranging from 0 to 255, which was obtained using Image Tool II software. The correlation between CHL1 and PCNA was evaluated via Pearson's correlation analysis, using SPSS software (version 17.0; SPSS Inc.).

Statistical analysis. In vitro experiments were repeated at least 3 times using independent culture preparations. All numerical data are presented as group mean \pm standard error of the mean. Statistical analyses were performed using SPSS version 10.0
(SPSS, Inc.). The analysis of CHL1 levels in glioma samples was undertaken using one-way ANOVA followed by Tukey's post hoc test. The effects of NRG1s on CHL1 were analyzed using one-way ANOVA followed by Dunnett's post hoc test. $\mathrm{P}<0.05$ was considered to indicate a statistically significant difference.

\section{Results}

Immunohistochemical staining of CHL1 in the glioma tissue microarray. Human tissues from a commercial glioma tissue microarray were subjected to H\&E staining and immunohistochemical staining of CHL1. Representative staining from the CAN tissue and tissues of different grades is shown in Fig. 1A. $\mathrm{H} \& \mathrm{E}$ staining showed regularly arranged cells in the CAN tissue, whereas abnormally proliferating cells were observed in the structurally disordered glioma tissues graded from I to IV (Fig. 1A), CHL1 was weakly stained in the CAN tissue, whereas it was strongly expressed in glioma tissue graded from I to IV, with the highest staining intensity detected in one grade II glioma tissue (Fig. 1A). The percentage of CHL1-positive area in each tissue point was measured to evaluate the expression levels of CHL1. As shown in Fig. 1B, the percentages of CHL1 positivity in CAN, and grade I, I-II, II, III and IV tumor tissues, were $32.33 \pm 5.00,52.61 \pm 2.91,66.67 \pm 4.43,64.58 \pm 2.85$, $46.67 \pm 5.92$ and $42.90 \pm 5.33 \%$, respectively. As was indexed by the percentage of CHL1-positive area in each tissue point, CHL1 expression levels in I-II and II grade gliomas were significantly higher compared with that in CAN tissue samples ( $\mathrm{P}<0.05$ for grade I-II and $\mathrm{P}<0.001$ for grade II). By contrast, CHL1 expression levels in grade IV tissues were significantly lower than those in grade I-II samples $(\mathrm{P}<0.05)$. In addition, the CHL1 expression levels in grade III and IV tissues were significantly lower than those in grade II samples $(\mathrm{P}<0.05$ for grade III and $\mathrm{P}<0.001$ for grade IV). It was thus concluded that CHL1 expression levels is associated with the malignancy of glioma.

To identify the differential expression of CHL1 between low-grade and high-grade gliomas, the distribution of CHL1 expression between gliomas graded II and IV were further compared. Fig. 1C-a and -e showed one grade IV and grade II tissue containing both low-cell-density and high-cell-density areas, and Fig. 1C-i showed one grade II tissue only with a low-cell-density area, as revealed by H\&E staining. The limited distribution of CHL1 in grade IV and II glioma tissues and the scattered distribution of CHL1 in grade II are presented in Fig. 1C-b, -f and -j, respectively. Fig. 1C-b and -d showed a restricted CHL1 expression in one grade IV glioblastoma, and that CHL1 expression level was associated with cell density within the glioma tissue. Generally, CHL1 was distributed in low-cell-density areas (Fig. 1C-d), while it was not notably expressed in high-cell-density areas (Fig. 1C-c). Similarly, CHL1 was largely expressed in the cell sparse areas in grade II glioma tissues (Fig. 1C-f, -h and -h'), with limited distribution found in the cell dense area (Fig. 1C-f, $-g$ and $-g^{\prime}$ ). In grade II gliomas with a scattered cell distribution, CHL1 was also dispersedly localized (Fig. 1C-j). Taken together, these results indicated that $\mathrm{CHL1}$ was predominately expressed in low-cell-density area relative to that in the high-cell-density area within the glioma tissue. 
A

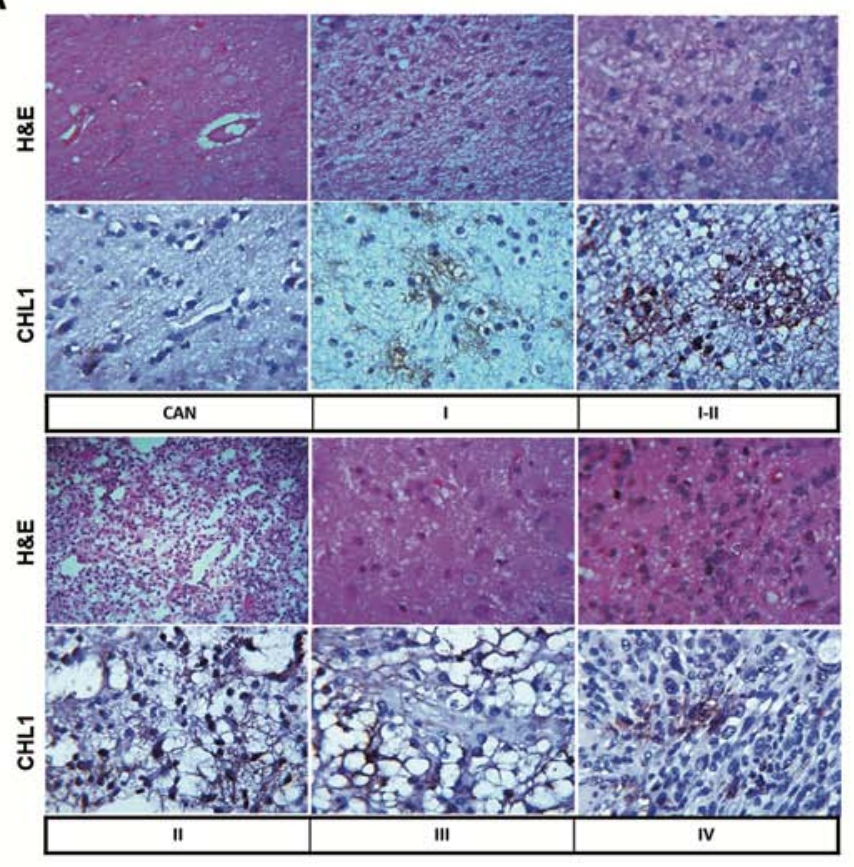

B

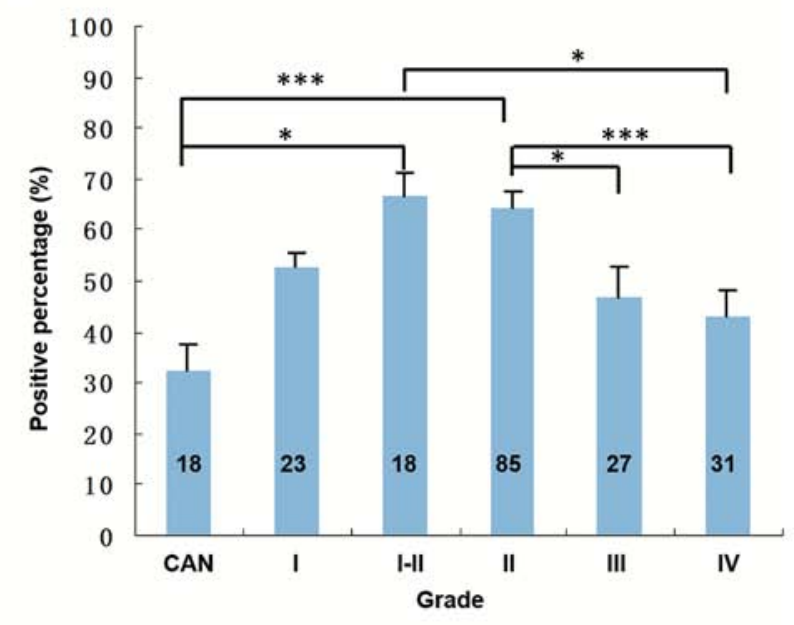

C
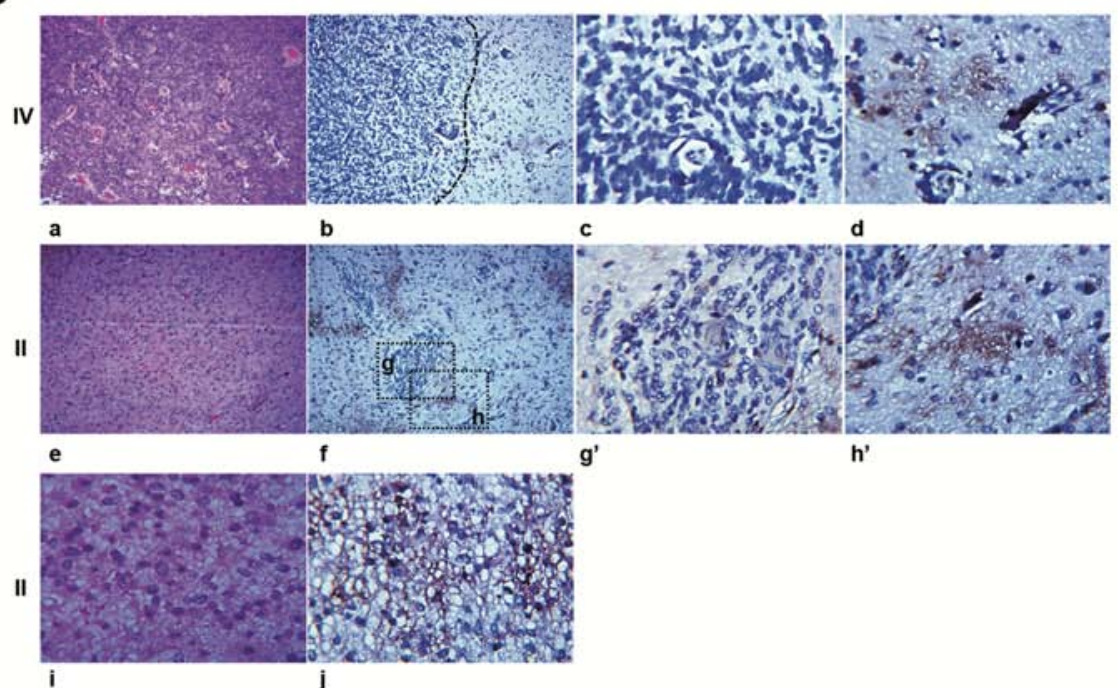

d

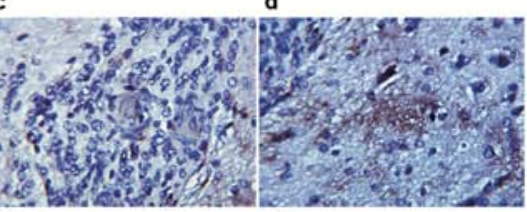

h'

Figure 1. CHL1 expression levels in human glioma tissues. (A) Human glioma tissues were subjected to H\&E and immunohistochemical staining for CHL1. (B) Percentage of CHL1-positive areas in each tissue point was measured to evaluate the expression levels of $\mathrm{CHL} 1$. ${ }^{*} \mathrm{P}<0.05$ and ${ }^{* * * *} \mathrm{P}<0.001$. (C) $\mathrm{H} \& \mathrm{E}$ staining of one grade IV glioma tissue (a) containing both low-cell-density and high-cell-density areas, (b) in which CHL1 expression was shown. In contrast to the weak CHL1 staining intensity in the (c) high-cell-density area of the grade IV glioma tissue, the staining intensity of CHL1 was relatively high in the (d) low-cell-density area of the tissue. H\&E staining of one grade II glioma tissue (e) containing both low-cell-density and high-cell-density areas, (f) in which CHL1 expression was shown. In contrast to the weak CHL1 staining intensity in the ( $\mathrm{g}$ and g') high-cell-density area of the grade II glioma tissue, the staining intensity of CHL1 was relatively high in the (h and $\left.h^{\prime}\right)$ low-cell-density area of the tissue. H\&E staining of one grade II glioma tissue that only exhibited a (i) low-cell-density area. (j) CHL1 was highly expressed in the grade II glioma tissue only with a low-cell-density area. g', the enlarged boxed region g, and h', the enlarged boxed region h. CHL1, cell adhesion molecule L1 like; CAN, cancer adjacent normal tissue. H\&E, hematoxylin and eosin.

Correlation between CHL1 and PCNA expression levels in human glioma tissues, and the effects of CHL1 on glioma cell senescence. First, the colocalization of CHL1 and PCNA in human glioma tissues was analyzed. Representative staining of CHL1 and PCNA are shown, in CAN and grade I-II and II human glioma tissues, in which the expression levels of CHL1 is highly expressed relative to that in the other grades of gliomas (Fig. 2A). In CAN tissue, both PCNA and CHL1 were weakly colocalized in the nucleus. In one grade I-II sample, CHL1 was solely localized on the cell membrane, while PCNA was weakly detected in the nucleus. However, in one grade II sample, CHL1 was not only detected on the cell membrane but it was also detected in the nucleus, where intensive colocalization with PCNA was observed. These data led to the hypothesis that CHL1 expression levels may be associated with the proliferation level of glioma cells. The correlation between CHL1 and PCNA on human gliomas of each grade was then evaluated.

Correlations between CHL1 and PCNA expression levels in the microarray data of human glioma tissues $(n=23,18,85$, 
A

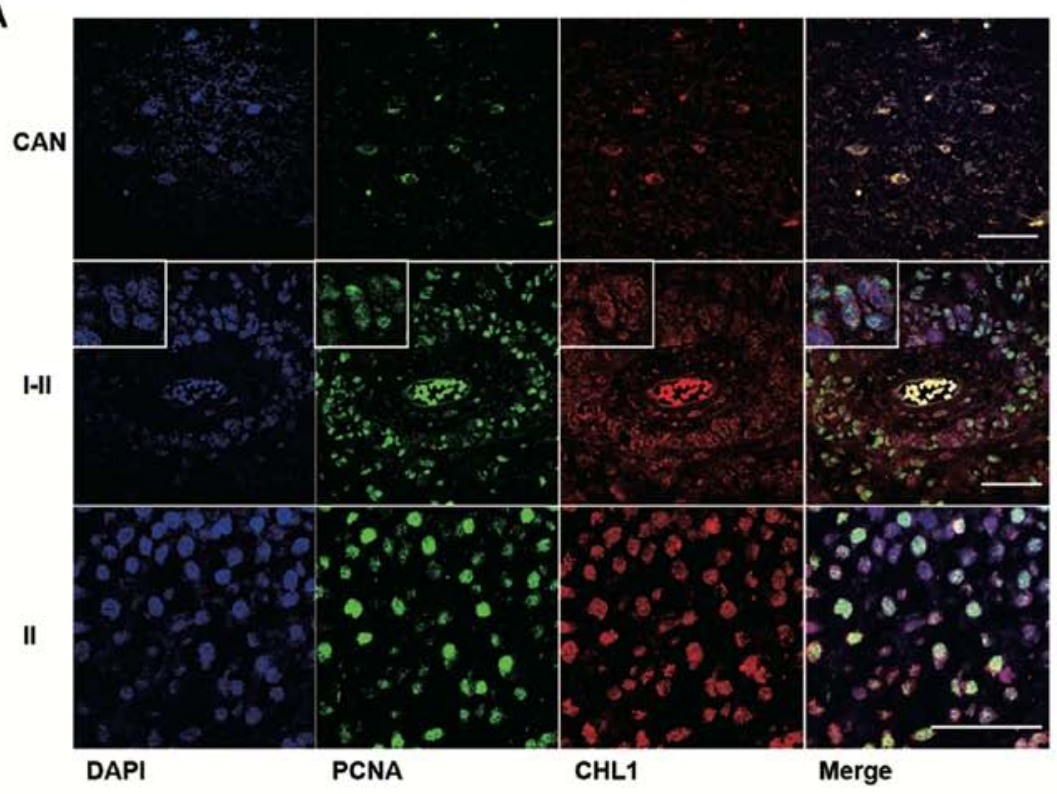

B

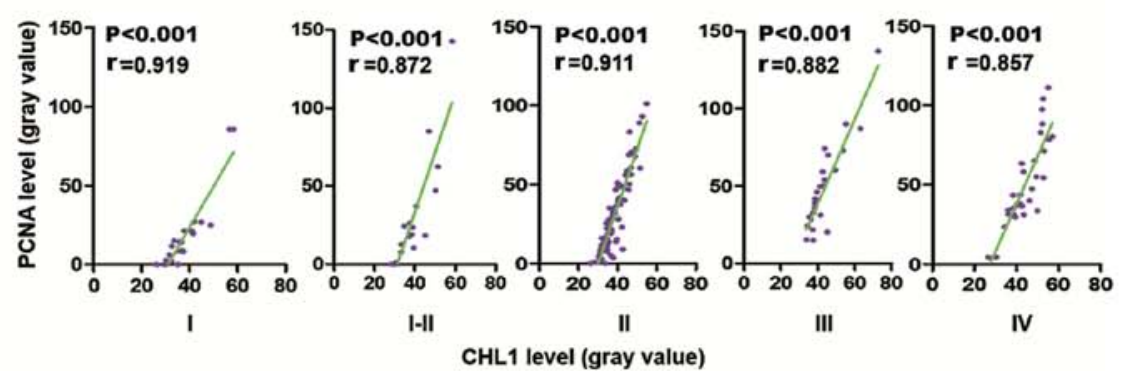

C
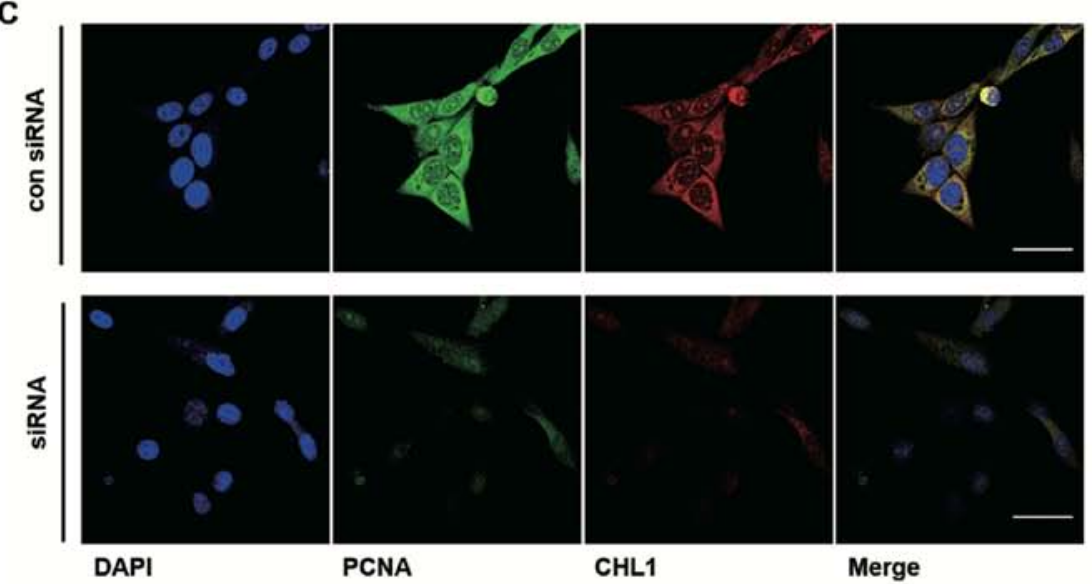

D

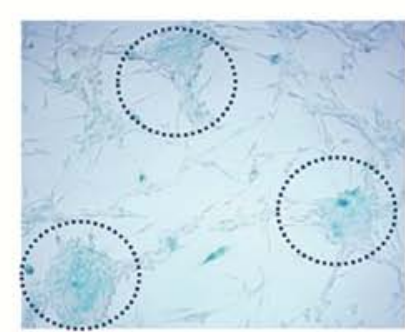

con SIRNA

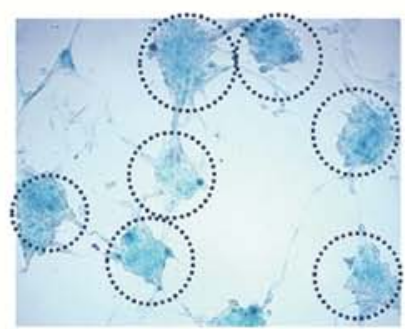

SiRNA

Figure 2. CHL1 expression level is correlated with PCNA expression levels in different grades of human gliomas, and downregulation of CHL1 induces glioma cell senescence. (A) Representative immunofluorescence staining of PCNA and CHL1 in CAN and human glioma tissues (graded I-II and II). Scale bars, $50 \mu \mathrm{m}$. (B) Correlation between CHL1 and PCNA expression levels ( $\mathrm{n}=23,18,85,27$ and 11 for I, I-II, II, III and IV grades, respectively). (C) Immunofluorescence staining of CHL1 and PCNA in U-87 MG cells treated with either a control siRNA or an siRNA targeting CHL1 for $48 \mathrm{~h}$. Downregulation of CHL1 resulted in the reduction of PCNA expression levels. Scale bars, $25 \mu \mathrm{m}$. (D) Enhanced staining of senescence-associated $\beta$-galactosidase was observed in cells with CHL1 knockdown, suggesting that CHL1 may function by delaying the senescence of glioblastoma cells. CHL1, cell adhesion molecule L1 like; PCNA, proliferation cell nuclear antigen; si, small interfering; con, control. 
A

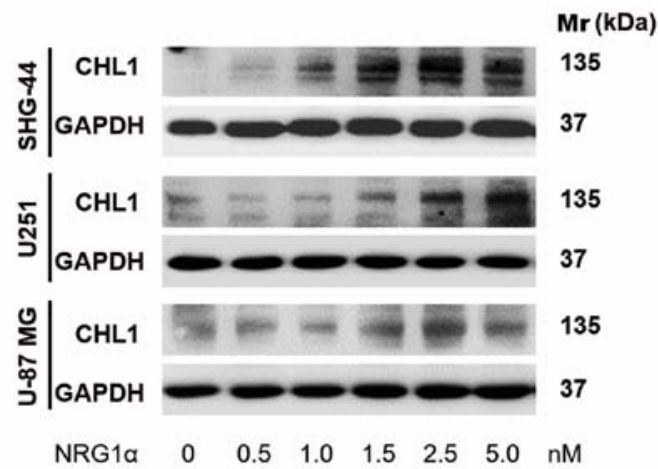

B
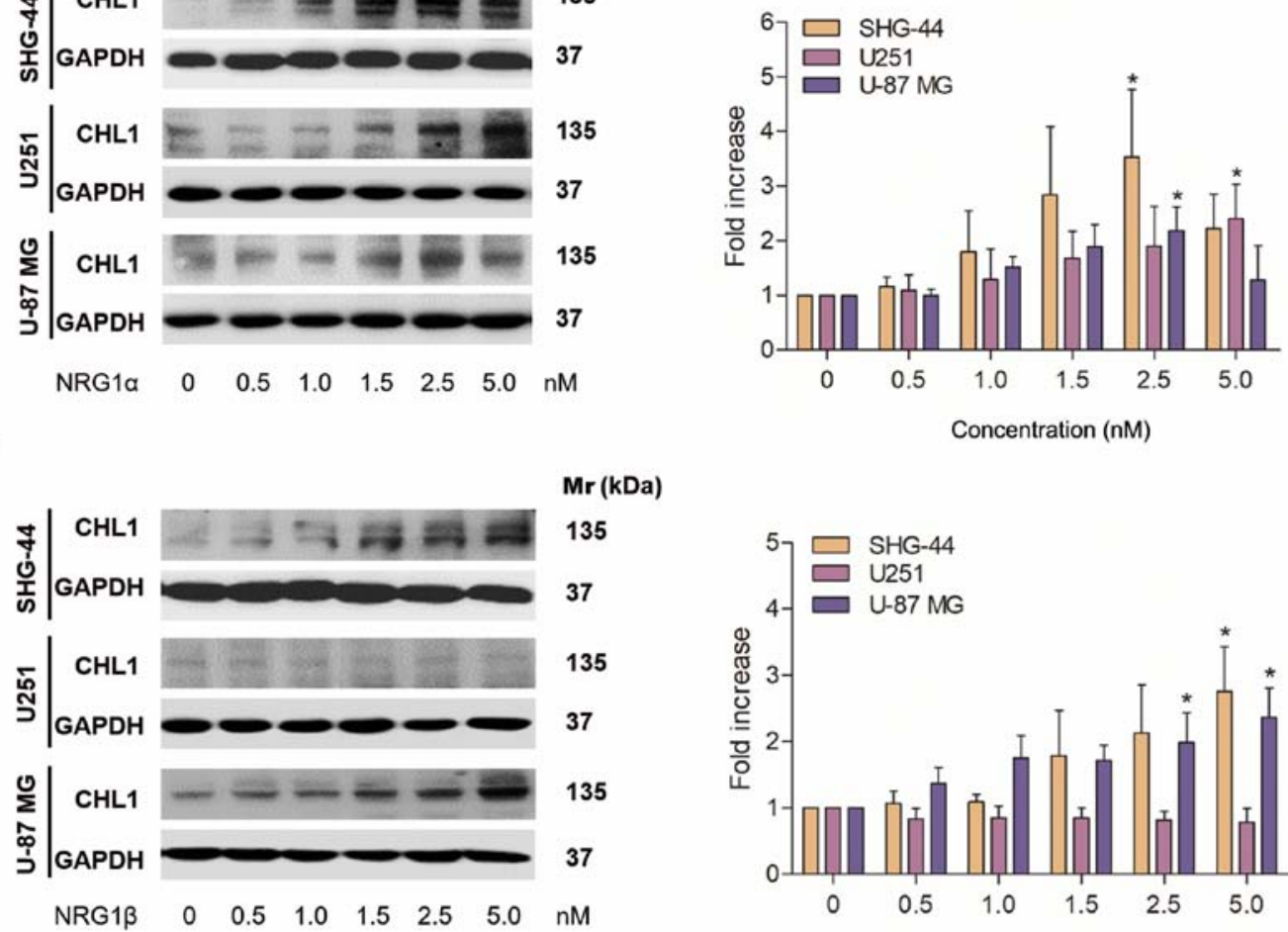

C
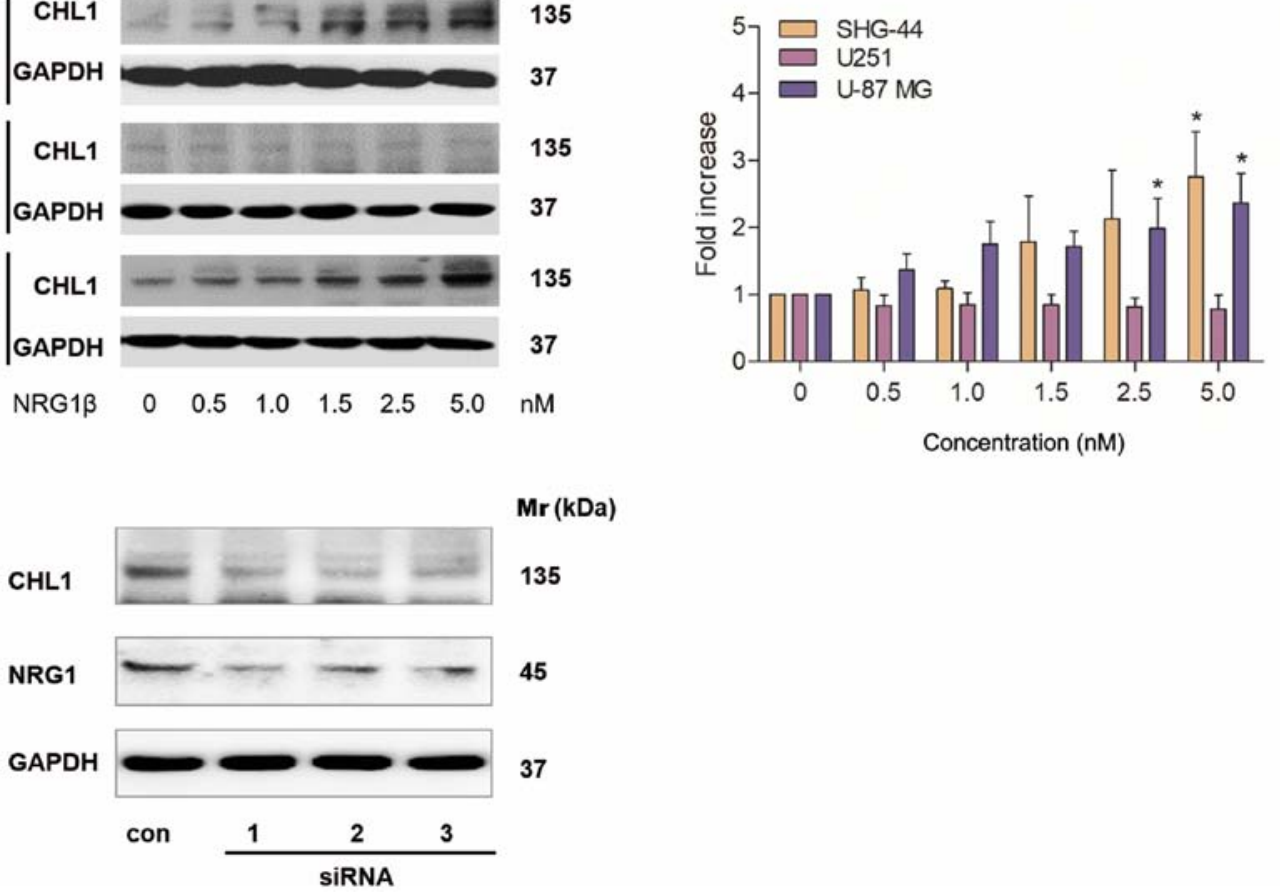

Figure 3. Western blot analysis of CHL1 expression levels in cultured SHG-44 and U251 human glioma and U-87 MG human glioblastoma cells in response to $48 \mathrm{~h}$ of treatment with (A) NRG1 $\alpha$ or (B) NRG1 $\beta$ at doses ranging from 0 to $5.0 \mathrm{nM}$. (C) A total of 3 siRNAs targeting NRG1 reduced NRG1 and CHL1 expression levels. "P<0.05. CHL1, cell adhesion molecule L1 like; NRG1, neuregulin 1; si, small interfering; Mr, molecular mass.

27 and 11 for grades I, I-II, II, III and IV, respectively) were then analyzed using Pearson's correlation (Fig. 2B). R values derived from Pearson correlation assay were 0.919, 0.872, $0.911,0.882$, and 0.857 in I, I-II, II, III and IV-grade glioma tissues, respectively, suggesting that CHL1 expression levels were highly positively correlated with the expression of PCNA and that CHL1 may modulate the proliferation of glioma cells, as indicated by PCNA. Immunofluorescence staining of CHL1 and PCNA was undertaken in U-87 MG cells treated with either control siRNA or siRNA targeting CHL1. The results demonstrated that downregulation of CHL1 resulted in the reduction of PCNA expression levels, suggesting that CHL1 regulates glioma cell proliferation (Fig. 2C).

To investigate whether downregulation of CHL1 can lead to cell senescence, senescence staining was conducted using a $\beta$-galactosidase activity assay. Enhanced senescence was observed in U-87 MG cells treated with an siRNA targeting CHL1. Compared with the negative control siRNA, cells treated with an siRNA targeting CHL1 demonstrated greater staining intensity by $48 \mathrm{~h}$ as shown in the dotted circle, which is indicative of a higher $\beta$-galactosidase activity and suggests that glioblastoma cells with less CHL1 activity are more prone to senescence (Fig. 2D).

Western blot analysis of CHL1 protein expression levels in response to NRG1 in 3 human glioma cell lines. Different concentrations of NRG1 $\alpha$ and $\beta$ were added to SHG-44 and U251 human glioma and U-87 MG human glioblastoma cells, and western blotting was used to investigate the effects of the different NRG1 isoforms on CHL1 protein expression levels. A total of $48 \mathrm{~h}$ after the application, NRG1 $\alpha$ treatment resulted in a dose-dependent increase in the protein expression levels of CHL1 in both SHG-44 and U251 cells, with the highest levels observed at 2.5 and $5 \mathrm{nM}$, respectively. In U-87 MG cells, CHL1 levels were significantly increased in cells treated with 1.0-2.5 nM NRG1 $\alpha$, with the highest level observed 

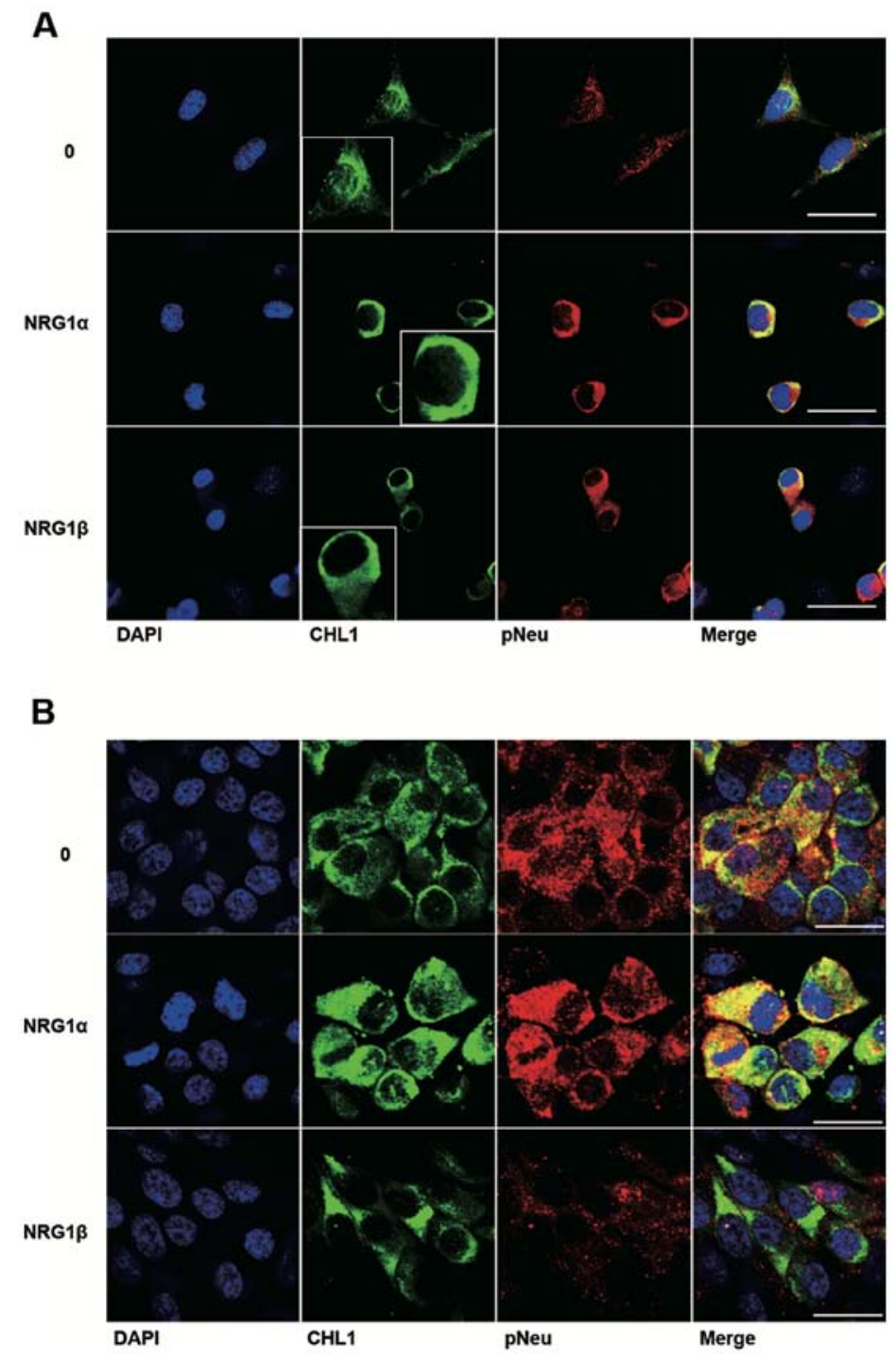

Figure 4. Expression levels and localization of CHL1 in U251 human glioma cells and U-87 MG human glioblastoma cells in response to treatment with $2.5 \mathrm{nM}$ NRG1s. U251 and U-87 MG cells were treated with $2.5 \mathrm{nM} \mathrm{NRG1} \alpha$ and NRG1 $\beta$ for $48 \mathrm{~h}$. The cells were then fixed and immunostained for CHL1 (green) and p-Neu (red), and then counterstained with DAPI (blue). Representative immunofluorescence staining showing the effects of NRG1 $\alpha$ and NRG1 $\beta$ on CHL1 expression levels and localization in (A) U251 and (B) U-87 MG cells., Scale bars 30 and $20 \mu \mathrm{m}$, respectively. CHL1, cell adhesion molecule L1 like; NRG1, neuregulin 1; NEU, ErbB2 receptor; p, phosphorylated.

following $2.5 \mathrm{nM}$ treatment (Fig. 3A). Statistical significances were found in SHG44 an U-87 MG cells treated with $2.5 \mathrm{nM}$

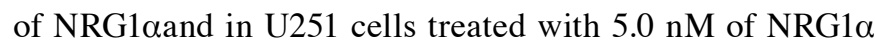
( $\mathrm{P}<0.05$; Fig. 3A).

A total of $48 \mathrm{~h}$ after application, NRG1 $\beta$ treatment resulted in a dose-dependent increase in the expression levels of CHL1 in both SHG-44 and U-87 MG cells, with the highest level observed at $5.0 \mathrm{nM}$ (Fig. 3B). In contrast, NRG1 $\beta$ showed no significant effects on CHL1 expression levels at any of the concentrations (Fig. 3B).

Statistical significances were found in SHG44 cells treated with both 2.5 and $5.0 \mathrm{nM}$ of NRG1ßand in U-87 MG cells treated with $5.0 \mathrm{nM}$ of NRG1 $\beta(\mathrm{P}<0.05$; Fig. 3B).

Subsequently U-87 MG glioblastoma cells, whose malignancy is relatively high, were treated with a control siRNA and 3 individual NRG1 siRNAs for $48 \mathrm{~h}$. The siRNA results demonstrated that all siRNAs targeting NRG1 markedly reduced the protein level of NRG1, which was accompanied by a reduction in CHL1 (Fig. 3C). Since all the three siRNAs worked in reducing the targeted protein NRG1, no statistical analysis was applied.

Colocalization of CHL1 and p-Neu in U251 human glioma and U-87 MG human glioblastoma cells treated with NRG1 $\alpha$ and NRG1 $\beta$. Among the ErbB receptors for NRG1, NEU is a commonly shared receptor that can form heterodimers with either ErbB3 or ErbB4 (14). The colocalization of CHL1 and p-Neu was further investigated as a result of NRG1 activation in both U251 human glioma cells and U-87 MG human glioblastoma cells. The cell lines were treated with both NRG1s at $2.5 \mathrm{nM}$, a concentration at which NRG1s can sufficiently work in both cell lines. The immunofluorescence staining results demonstrate that NRG1 $\alpha$ increased the protein level of CHL1 in the cytoplasm and at the plasma membrane of U251 cells. Consistent with the western blot results, NRG1 $\beta$ failed to increase the expression levels of CHL1 at $2.5 \mathrm{nM}$, although increased activation of p-Neu was detected in U251 cells (Fig. 4A). The immunofluorescence staining results 

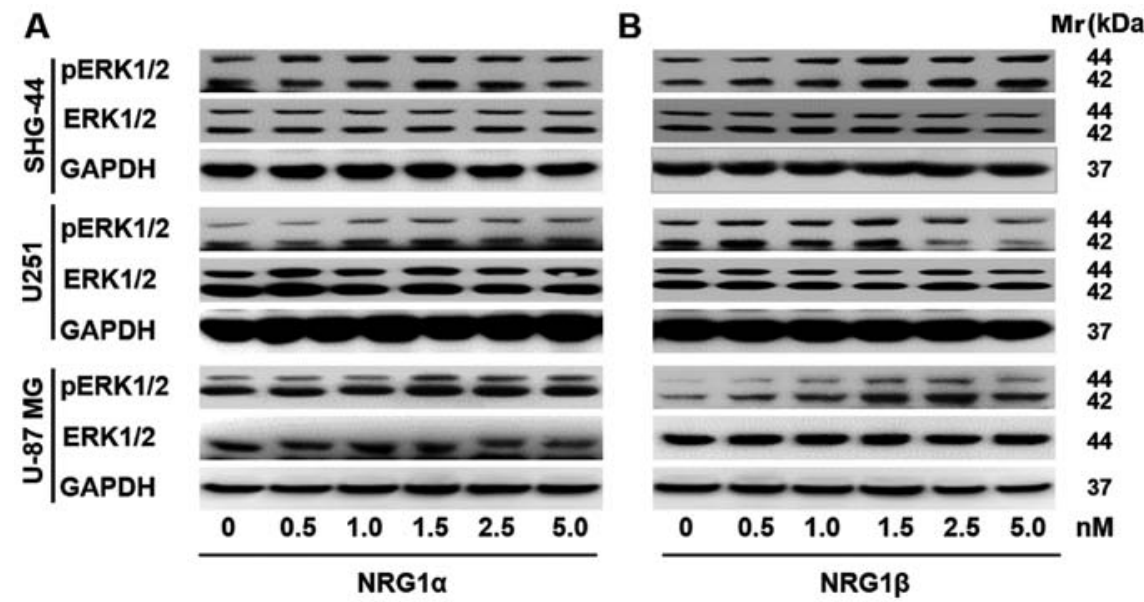

Figure 5. Effects of NRG1s on the expression levels of p-ERK1/2 in U-87 MG cells. Representative images showing western blot analysis for p-ERK1/2 in SHG-44, U251 and U-87 MG human glioma/glioblastoma cells in response to (A) NRG1 $\alpha$ or (B) NRG1 $\beta$ at doses ranging from 0 to $5.0 \mathrm{nM}$. NRG1, neuregulin 1 ; p, phosphorylated.

demonstrate that both NRG1 $\alpha$ and NRG1 $\beta$ increased CHL1 expression levels in the cytoplasm and at the plasma membrane of U-87 MG cells. However, the fluorescence signaling of p-Neu was not increased following treatment with NRG1 $\beta$ at $2.5 \mathrm{nM}$ (Fig. 4B).

Effects of NRG1 on ERK1/2 signaling in human glioma cells. Accumulating evidence has indicated that the Ras/MAPK/ERK signaling pathways contribute to cell growth, proliferation and survival (1). Thus, western blot analysis was performed to assess p-ERK1/2 expression levels in U251, SHG-44 and U-87 MG cells in response to treatment with NRG1s. It was demonstrated that $\mathrm{p}$-ERK $1 / 2$ protein expression levels were upregulated in U251 and U-87 MG human glioma/glioblastoma cells in response to $48 \mathrm{~h}$ of rNRG1 $\alpha$ treatment, and that the response was dose-dependent; however, rNRG1 $\alpha$ showed no effect on the protein expression levels of p-ERK1/2 in the SHG-44 human glioma cell line (Fig. 5A). Similarly, rNRG1 $\beta$ increased p-ERK $1 / 2$ expression levels in a dose-dependent manner in SHG-44, U251 and U-87 MG cells. The p-ERK1/2 expression levels peaked when the rNRG1 $\beta$ concentration was $1.5 \mathrm{nM}$ and then p-ERK1/2 expression levels gradually returned to the baseline level (Fig. 5B).

\section{Discussion}

Previous studies have demonstrated that both NRG1 and CHL1 serve roles in the development, proliferation and metastasis of glioma cells $(15,24)$. However, the association between NRG1 signaling and CHL1 in these processes has not been fully elucidated. The present study demonstrated that, for the first time, the tumor-associated cytokine NRG1 can regulate CHL1 expression levels in gliomas and that this is associated with glioblastoma grade. In addition, these data suggest that NRG1 may function in this underlying mechanism, contributing to malignancy by upregulating CHL1 expression levels in glioblastoma cells.

CHL1 is important for the normal development of the visual and somatosensory cortex (25). A study in CHL1-deficient mice revealed that CHL1 can facilitate the radial migration of neuronal precursors to suitable cortical lamellas in deep-layered pyramid neurons (25). In the adult brain, CHL1 functions as a key regulator of synapse formation and synaptic activity in the maintenance and rehabilitation of neural circuits (26). CHL1 is also associated with the metastasis and invasion of malignant tumors, such as glioma, melanoma, ovarian cancer, colon carcinoma and breast cancer (21). However, the roles of CHL1 in tumor development and progression remain unclear. In previous research, CHL1 was found to function as a tumor suppressor during primary tumor growth (27) and it was reported that CHL1 expression levels were decreased in human breast cancer with a low malignancy grade (27), whereas downregulation of CHL1 expression levels by the targeting of microRNA (miR)-10a enhanced the migration and invasion properties of human cervical cancer cells (20). In contrast to these diverse findings regarding CHL1 in most types of cancer, our previous research revealed that CHL1 functions in promoting cell proliferation, metastasis and migration of human glioma cells both in vitro and in vivo, suggesting a positive association between CHL1 level and glioma grade (28).

The present results from the glioma tissue microarray staining demonstrated that CHL1 is highly expressed in glioma tissues of each grade, with the highest expression level detected in gliomas graded II. As indicated by correlation analysis between CHL1 and PCNA, CHL1 was highly correlated with glioma cell proliferation in grade I-II gliomas, which may facilitate the determination of the grade of glioma malignancy. Delayed cellular aging-related uncontrolled proliferation has been a major drug-resistance factor in the treatment of glioma $(29,30)$. The extent of cellular senescence can be determined by the levels of lysosomal- $\beta$-galactosidase activity (31). In the present study, glioma cells treated with CHL1 siRNA exhibited significant signs of senescence, suggesting that CHL1 may promote glioma growth by inhibiting cell senescence; thus, CHL1 is associated with glioma malignancy grade.

Both isoforms of NRG1 protein ( $\alpha$ and $\beta$ ) contain structurally distinct EGF-like domains that contain a common amino terminal segment followed by $\alpha$ and $\beta$ variant sequences, 
respectively (14). The NRG1/ErbB receptor interaction serves an important role in modulating the development of human astrocytic glioma cells (15). Thus, the interaction between NRG1 and its ErbB receptors may consequently enhance intercellular communication through cell-cell or cell-extracellular matrix interaction (22). In particular, NRG1 $\alpha$ induces marked proliferation in human transitional cell carcinomas by binding to the ErbB4 receptor, indicating the existence of an autocrine pathway $(13,14)$. NRG1 $\alpha$ also stimulates cell proliferation mediated by multiple matrix metalloproteases during tumor cell migration (10). Another study demonstrated that the expression levels of NRG1 $\beta$ were significantly increased in melanoma cell lines (32). These previous studies indicated that both CHL1 and NRG1 are involved in the invasion and reduced apoptosis of glioma cells.

Hyperactivation of the PI3K/AKT signaling pathway is frequently reported in a variety of cancers, including glioblastoma multiforme, where the PI3K/AKT signaling pathway regulates tumor cell survival, growth, motility, angiogenesis and metabolism $(33,34)$. Glioblastoma has been found to overexpress mutated epidermal growth factor receptor, which in turn leads to the activation of several downstream signaling pathways, such as the phosphatidylinositol PI3K/AKT/mammalian target of rapamycin (mTOR) pathway (35). Research on PI3K inhibitors, including pan-PI3K inhibitors, isoform-selective inhibitors and dual $\mathrm{PI} 3 \mathrm{~K} / \mathrm{mTOR}$ inhibitors has provided valuable insight into the treatment of a variety of malignancies, such as breast, prostate and lung cancers, and mesothelioma, sarcoma and lymphoma (36). Furthermore, the combination of inhibitors targeting PI3K and the PI3K/AKT/mTOR signaling pathway can contribute to the suppression of tumor growth and improve prognosis (36). In a previous study, it was reported that activation of Akt1 is reduced by CHL1 downregulation, while no significant effects were observed regarding ERK1/2 activation, indicating that the effects of CHL1 on the behavior of glioma are possibly mediated by the Akt1 signaling pathway (28). Other research revealed that NRG1 $\beta$ promotes survival of glioma cells, while inhibiting apoptosis of glioma cells via the PI3K/AKT signaling pathway $(15,37)$.

Similar to the PI3K/AKT signaling pathway, the Ras/MAPK/ERK signaling pathway is also involved in the proliferation and survival of malignant glioma cells (33). miR-126 regulates the ERK pathway by targeting KRAS to inhibit the proliferation and invasion of glioma cells (38). Blocking the MAPK/ERK signaling pathway can inhibit the progression of glioma (39). Our previous study demonstrated a positive association between the expression levels of CHL1 and Akt1 activation with no significant effect of CHL1 on ERK1/2 activation (28). In the present study, both NRG1 $\alpha$ and $\beta$ isoforms were reported to activate the ERK signaling pathway. Specifically, NRG1 $\alpha$ participates in the activation of the ERK signaling pathway in U251 and U-87 MG glioma cells, but not in SHG-44 human glioma cells. NRG1 $\beta$ activates the ERK signaling pathway in U-87 MG and SHG-44 human glioma/glioblastoma cells, but showed no observable effect in $\mathrm{U} 251$ human glioma cells. NRG1 $\alpha$ and NRG1 $\beta$ may act synergistically or compensate for each other to increase the level of survival, proliferation, invasion and metastasis via CHL1 enhancement.
In summary, the results of the present study suggested that NRG1 modulates the growth and proliferation of glioma cells, and may contribute to the malignancy of glioma, as an upstream signaling molecule of CHL1. NRG1 may function by enhancing CHL1 via the ERK1/2 signaling pathway. The variable effects of the isoforms of NRG1 on the 3 different glioma cell lines may be ascribed to variation in the expression levels of molecules that interact with NRG1, a characteristic that currently complicates glioma/glioblastoma treatment. Further investigation may provide insights into the development of inhibitors to antagonize NRG1-induced CHL1 expression in the clinical management of glioma.

\section{Acknowledgements}

The authors would like to thank Mr. Huifan Shen from the Center for Neuroscience at Shantou University Medical College (Shantou, China) for his assistance in the maintenance of the cell culture room.

\section{Funding}

The present study was supported by The National Natural Science Foundation of China (grant nos. 81471279 and 81171138) and The Research Start-Up Fund of Wuxi School of Medicine, Jiangnan University (grant no. 1286010242190060).

\section{Availability of data and materials}

The datasets used and/or analyzed during the current study are available from the corresponding author on reasonable request.

\section{Authors' contributions}

WJZ designed the study and drafted the initial manuscript. WJZ and WWL collated the data. WWL, GYO, JZL, SJY, HCP and WCY analyzed the data and wrote the initial draft of the manuscript. WJZ and HCP critically revised the manuscript for important intellectual content. All authors read and approved the final manuscript.

\section{Ethics approval and consent to participate}

Not applicable.

\section{Patient consent for publication}

Not applicable.

\section{Competing interests}

The authors declare that they have no competing interests.

\section{References}

1. Wen PY and Kesari S: Malignant gliomas in adults. N Engl J Med 359: 492-507, 2008.

2. Sathornsumetee S, Reardon DA, Desjardins A, Quinn JA, Vredenburgh JJ and Rich JN: Molecularly targeted therapy for malignant glioma. Cancer 110: 13-24, 2007. 
3. Davis ME: Glioblastoma: Overview of disease and treatment Clin J Oncol Nurs 20 (5 Suppl): S2-S8, 2016.

4. Stupp R, Hegi ME, Mason WP, van den Bent MJ, Taphoorn MJ, Janzer RC, Ludwin SK, Allgeier A, Fisher B, Belanger K, et al: Effects of radiotherapy with concomitant and adjuvant temozolomide versus radiotherapy alone on survival in glioblastoma in a randomised phase III study: 5-year analysis of the EORTC-NCIC trial. Lancet Oncol 10: 459-466, 2009.

5. Ostrom QT, Bauchet L, Davis FG, Deltour I, Fisher JL, Langer CE, Pekmezci M, Schwartzbaum JA, Turner MC, Walsh KM, et al: The epidemiology of glioma in adults: A 'state of the science' review. Neuro Oncol 16: 896-913, 2014.

6. Morgan MA and Canman CE: Replication stress: An achilles' heel of glioma cancer stem-like cells. Cancer Res 78: 6713-6716, 2018.

7. Weller M, van den Bent M, Tonn JC, Stupp R, Preusser M, Cohen-Jonathan-Moyal E, Henriksson R, Rhun EL, Balana C, Chinot $\mathrm{O}$, et al: European association for neuro-oncology (EANO) guideline on the diagnosis and treatment of adult astrocytic and oligodendroglial gliomas. Lancet Oncol 18: e315-e329, 2017.

8. Nilsson P, Gedda L, Sjöström A and Carlsson J: Effects of dextranation on the uptake of peptides in micrometastases: Studies on binding of EGF in tumor spheroids. Tumour Biol 22: 229-238, 2001.

9. Thuringer D, Hammann A, Benikhlef N, Fourmaux E, Bouchot A, Wettstein G, Solary E and Garrido C: Transactivation of the epidermal growth factor receptor by heat shock protein 90 via Toll-like receptor 4 contributes to the migration of glioblastoma cells. J Biol Chem 286: 3418-3428, 2011.

10. O-charoenrat P, Rhys-Evans P, Court WJ, Box GM and Eccles SA: Differential modulation of proliferation, matrix metalloproteinase expression and invasion of human head and neck squamous carcinoma cells by c-ErbB ligands. Clin Exp Metastasis 17: 631-639, 1999.

11. Forster JA, Paul AB, Harnden P and Knowles MA: Expression of NRG1 and its receptors in human bladder cancer. Br J Cancer 104: 1135-1143, 2011.

12. Cheng H, Terai M, Kageyama K, Ozaki S, McCue PA, Sato T and Aplin AE: Paracrine effect of NRG1 and HGF drives resistance to MEK inhibitors in metastatic uveal melanoma. Cancer Res 75 2737-2748, 2015

13. Yarden Y and Sliwkowski MX: Untangling the ErbB signalling network. Nat Rev Mol Cell Biol 2: 127-137, 2001.

14. Buonanno A and Fischbach GD: Neuregulin and ErbB receptor signaling pathways in the nervous system. Curr Opin Neurobiol 11: 287-296, 2001

15. Ritch PS, Carroll SL and Sontheimer H: Neuregulin-1 enhances survival of human astrocytic glioma cells. Glia 51:217-228, 2005.

16. Senchenko VN, Krasnov GS, Dmitriev AA, Kudryavtseva AV, Anedchenko EA, Braga EA, Pronina IV, Kondratieva TT, Ivanov SV, Zabarovsky ER and Lerman MI: Differential expression of CHL1 gene during development of major human cancers. PLoS One 6: e15612, 2011

17. Schmid RS and Maness PF: L1 and NCAM adhesion molecules as signaling coreceptors in neuronal migration and process outgrowth. Curr Opin Neurobiol 18: 245-250, 2008

18. Panicker AK, Buhusi M, Thelen K and Maness PF: Cellular signalling mechanisms of neural cell adhesion molecules. Front Biosci 8: d900-d911, 2003

19. Sasaki H, Yoshida K, Ikeda E, Asou H, Inaba M, Otani M and Kawase T: Expression of the neural cell adhesion molecule in astrocytic tumors: An inverse correlation with malignancy. Cancer 82: 1921-1931, 1998.

20. Long MJ, Wu FX, Li P, Liu M, Li X and Tang H: MicroRNA-10a targets CHL1 and promotes cell growth, migration and invasion in human cervical cancer cells. Cancer Lett 324: 186-196, 2012.

21. Liu Y, Yu Y, Schachner M and Zhao W: Neuregulin 1- $\beta$ regulates cell adhesion molecule L1 expression in the cortex and hippocampus of mice. Biochem Biophys Res Commun 441: 7-12, 2013
22. Zhao WJ and Schachner M: Neuregulin 1 enhances cell adhesion molecule 11 expression in human glioma cells and promotes their migration as a function of malignancy. J Neuropathol Exp Neurol 72: 244-255, 2013

23. Louis DN, Perry A, Reifenberger G, von Deimling A, FigarellaBranger D, Cavenee WK, Ohgaki H, Wiestler OD, Kleihues P and Ellison DW: The 2016 world health organization classification of tumors of the central nervous system: A summary. Acta Neuropathol 131: 803-820, 2016.

24. Ritch PA, Carroll SL and Sontheimer H: Neuregulin-1 enhances motility and migration of human astrocytic glioma cells. J Biol Chem 278: 20971-20978, 2003.

25. Demyanenko GP, Schachner M, Anton E, Schmid R, Feng G, Sanes J and Maness PF: Close homolog of L1 modulates area-specific neuronal positioning and dendrite orientation in the cerebral cortex. Neuron 44: 423-437, 2004

26. Sytnyk V, Leshchyns'ka I and Schachner M: Neural cell adhesion molecules of the immunoglobulin superfamily regulate synapse formation, maintenance, and function. Trends Neurosci 40: 295-308, 2017.

27. He LH, Ma Q, Shi YH, Ge J, Zhao HM, Li SF and Tong ZS: CHL1 is involved in human breast tumorigenesis and progression. Biochem Biophys Res Commun 438: 433-438, 2013.

28. Yang Z, Xie Q, Hu CL, Jiang Q, Shen HF, Schachner M and Zhao WJ: CHL1 is expressed and functions as a malignancy promoter in glioma cells. Front Mol Neurosci 10: 324, 2017.

29. Hanahan D and Weinberg RA: Hallmarks of cancer: The next generation. Cell 144: 646-674, 2011.

30. Fan HC, Chen CM, Chi CS, Tsai JD, Chiang KL, Chang YK, Lin SZ and Harn HJ: Targeting telomerase and ATRX/DAXX inducing tumor senescence and apoptosis in the malignant glioma. Int J Mol Sci 20: pii: E200, 2019.

31. Debacq-Chainiaux F, Erusalimsky JD, Campisi J and Toussaint O: Protocols to detect senescence-associated beta-galactosidase (SA-beta gal) activity, a biomarker of senescent cells in culture and in vivo. Nat Protoc 4: 1798-1806, 2009.

32. Alver TN, Lavelle TJ, Longva AS, Øy GF, Hovig E and Bøe SL: MITF depletion elevates expression levels of ERBB3 receptor and its cognate ligand NRG1-beta in melanoma. Oncotarget 7: 55128-55140, 2016

33. Asati V, Mahapatra DK and Bharti SK: PI3K/Akt/mTOR and Ras/Raf/MEK/ERK signaling pathways inhibitors as anticancer agents: Structural and pharmacological perspectives. Eur J Med Chem 109: 314-341, 2016.

34. Zhao HF, Wang J, Shao W, Wu CP, Chen ZP, To ST and Li WP: Recent advances in the use of PI3K inhibitors for glioblastoma multiforme: Current preclinical and clinical development. Mol Cancer 16: 100, 2017.

35. Li X, Wu C, Chen N, Gu H, Yen A, Cao L, Wang E and Wang L: $\mathrm{PI} 3 \mathrm{~K} / \mathrm{Akt} / \mathrm{mTOR}$ signaling pathway and targeted therapy for glioblastoma. Oncotarget 7: 33440-33450, 2016.

36. Rodon J, Dienstmann R, Serra V and Tabernero J: Development of PI3K inhibitors: Lessons learned from early clinical trials. Nat Rev Clin Oncol 10: 143-153, 2013.

37. Yin F, Zhang JN, Wang SW, Zhou CH, Zhao MM, Fan WH Fan M and Liu S: MiR-125a-3p regulates glioma apoptosis and invasion by regulating Nrg1. PLoS One 10: e0116759, 2015.

38. Li Y, Li Y, Ge P and Ma C: MiR-126 regulates the ERK pathway via targeting KRAS to inhibit the glioma cell proliferation and invasion. Mol Neurobiol 54: 137-145, 2017.

39. Li B, Wang F, Liu N, Shen W and Huang T: Astragaloside IV inhibits progression of glioma via blocking MAPK/ERK signaling pathway. Biochem Biophys Res Commun 491: 98-103, 2017.

This work is licensed under a Creative Commons Attribution-NonCommercial-NoDerivatives 4.0 International (CC BY-NC-ND 4.0) License. 